www.jmscr.igmpublication.org

Impact Factor 5.244

Index Copernicus Value: 83.27

ISSN (e)-2347-176x ISSN (p) 2455-0450

crossref DOI:_http://dx.doi.org/10.18535/jmscr/v4i8.02

\title{
An Etiological Study of Upper Gastro-intestinal Bleeding with Special Reference to Helicobacter Pylori Infection in Peptic Ulcer Disease
}

Authors

\section{Dr Ardhendu Kumar Sen ${ }^{1}$, Dr Priyam Goswami ${ }^{2}$, Dr Prasanta $\operatorname{Neog}^{3}$, Dr Anupam Dutta ${ }^{4}$, Dr Kalpana Chetia ${ }^{5}$}

${ }^{1}$ Professor of Medicine, ${ }^{2}$ Assistant Professor of Medicine, ${ }^{3}$ Postgraduate trainee,

${ }^{4}$ Assistant Professor of Medicine, ${ }^{5}$ Associate Professor of Medicine

$1,2,3,4,5$ Dept of Medicine, Assam Medical College and hospital, Dibrugarh, Assam, India

Email: ${ }^{1}$ draksen57@gmail.com, ${ }^{2}$ priyam014@ rediffmail.com, ${ }^{3}$ prasantaneog@ rediffmail.com,

${ }^{4}$ dranupamdutta@yahoo.com, ${ }^{5}$ kalpana.chetia@gmail.com

\begin{abstract}
OBJECTVE: Upper gastro intestinal bleeding is a common life threatening emergency resulting in a large number of hospital admission. Peptic ulcers are the most common cause of UGIB. Helicobacter pylori plays a pivotal role in the aetiology of peptic ulcer disease and eradication of infection has been known to alter the course of peptic ulcer disease. The present study was undertaken with the aim of studying the aetiological profile of upper gastrointestinal bleeding along with the frequency of helicobacter pylori infection in peptic ulcer disease.
\end{abstract}

MATERIALS AND METHODS: The total of 120 cases admitted between $1^{\text {st }}$ September 2010 to $31^{\text {st }}$ August 2011 and more than 13 years of age, presenting with haematemesis and or malaena were enrolled for the study. They were subjected to upper GI endoscopy after stabilisation. Causes of UGIB was assessed and biopsy material taken in patients with peptic ulcer disease for Rapid Urease test to detect presence of Hpylori.

RESULTS: The most common cause of UGIB was found to be peptic ulcer disease (54.16\%), followed by gastroesophageal varies $24.16 \%$, erosive mucosal disease (14.17\%), neoplastic lesion (3.33\%) malory weiss tear (1.67\%) and normal endoscopy was found in $2.5 \%$. Helicobacter pylori infection was found in $56.92 \%$ patients with peptic ulcer disease, with higher incidence in duodenal ulcers (62.54\%) then in gastric ulcer (48\%)

CONCLUSION: The present study shows that peptic ulcer disease is the most common cause of UGIB followed by gastro esophageal varices in this part of the country. Helicobacter pylori is commonly associated with peptic ulcer disease. Hence it should be detected and treatment initiated for the effective recovery.

Keywords- peptic ulcer, helicobacter pylori. 


\section{INTRODUCTION}

Upper gastrointestinal bleeding is a common life threatening emergency resulting in a large number of hospital admission. It accounts for over 300,000 annual hospital admission in United States ${ }^{1}$. Peptic ulcers are the most common cause of UGIB, accounting for upto $50 \%$ of cases ${ }^{2}$ Helicobactor pylori plays a pivotal role in aetiology of peptic ulcer disease and eradication of infection has been known to alter the course of peptic ulcer by promoting ulcer healing, reducing ulcer recurrence rate and its complication. (John Del Valle, 2018)

The prevalence of $\mathrm{H}$. pylori varies throughout the world and depends largely on standard of living in the region. Two factors that predispose to higher colonization rate includes poor socio economy status and less education ( John Del Valle.2008). Not many studies have been done on the aetiology of UGIB in this part of the country. With these fact in view, the study has been conducted to study the aetiological profile of UGIB and to study the frequency of helicobactor pylori infection in peptic ulcer disease.

\section{MATERIALS AND METHODS}

The present observational study was carried out in the department of medicine in Assam Medical College and Hospital, Dibrugarh from September 2010 to august 2011. The study was carried out on 120 cases presenting with UGIB with age more than or equal to 13 years. Patients presented with black tarry stool or vomiting of blood or both were taken up for study. Immediately following admission, vital signs of patients were assessed and resuscitated. Initial blood loss was combated with isotonic saline or synthetic colloid. Blood transfusion was given where required.

After haemodynamic stabilization, patients were subjected to thorough history taking and physical examination and routine laboratory test. Thereafter upper gastro intestinal endoscopy was done using the instrument Olympus Cv 70 to find the aetiology of UGIB. Biopsy material was taken in patients with peptic ulcer disease for Rapid Urease test to detect the presence of H.Pylori. Biopsy material was also taken for histopathological examination whenever suspected malignant lesion were found.

\section{RESULTS AND OBSERVATION}

Out of 120 patients with UGIB maximum number of patients $(29.16 \%)$ were in the age group of 41-50 years followed by $21.67 \%$ in the age group of 51-60 years. The age of patients ranged from 13-80 years with a mean of $46.92(+/-15.03 \mathrm{sd})$ years . A male preponderance was found with $84.17 \%$ versus female cases $(15.83 \%)$ the ratio being 5.32:1.

The most common clinical presentation was haematemesis and malaena (50\%), followed by malaena $(31.67 \%)$ and haematemesis alone $(18.33 \%)$ In this study chronic liver disease was found in $24.17 \%$ patients, chronic kidney disease in $1.67 \%$, hypertension in $8.33 \%$, diabetes mellitus in $3.33 \%$ and COPD in $2.50 \%$ patients

Upper GI endoscopy showed peptic ulcer disease to be the most common cause of GI bleed (54.16\%). Among them duodenal ulcer constituted 33.33\% and gastric ulcer $20.83 \%$. Second most common cause of UGIB was ruptured gastro esophageal varices $(24.16 \%)$, followed by gastric erosion $(9.17 \%)$, duodenal erosion (5\%), Mallory Weiss tear (1.67\%), esophageal growth (1.67\%), aderocarcinoma of stomach (1.67) and a normal endoscopic finding was found in $2.50 \%$ patients.

In this study peptic ulcer was found highest (26) in the age group of 41-50years, gastro esophageal varices were found highest between 41-50 years and gastro esopheageal neoplasm between the age group of 50 to 70 years.

The Rapid Urease test for helicobacter pylori infection was found positive in $56.92 \%$ of peptic ulcer disease. $\mathrm{H}$ pylori was found in $62.50 \%$ of duodenal ulcer $48.00 \%$ of gastric ulcer. $\mathrm{H}$ pylori was found only in $17.67 \%$ of erosive mucosal disease.

Amongst peptic ulcer \& erosive mucosal disease alcohol ingestion was found to be the commonest associated risk factor (35\%) followed by non steroidal anti inflammatory drug use (14.63\%), smoking (13.82\%) and steroid (3.25\%). Erosive mucosal disease was commonest endoscopic finding 
in those taking non-steroidal anti-inflammatory drugs $(77.78 \%)$ followed by gastric ulcer $(16.66 \%)$ and duodenal ulcer $(5.66 \%)$

Among those taking alcohol (42 patients) gastroesophageal varices was the commonest endoscopic finding $(69.05 \%)$ followed by erosive mucosal disease (16.67\%), peptic ulcer disease $(9.52 \%)$ and malory weiss tear $(4.76 \%)$.

\section{DISCUSSION}

Upper gastro intestinal bleed is a common medical emergency with significant and mortality.

In our study maximum (29.16\%) patients were of age group $41-50 y e a r s$, followed by $21.67 \%$ in the age group of 51-60 years. Age of patients ranged from 13 to 80 years with a mean age of 46.92 $( \pm 15.03$ SD) years. In a study by S. Mustapha, N.Ajayi and A. Shehu (2009) age ranged from 1475 years with mean of $41.2( \pm 15.1 \mathrm{SD})$ years ${ }^{(4)} \mathrm{A}$ Timraj et al (2011) showed patients ranged from 12100 years of age with a mean of 49 years ${ }^{(5)}$

A male preponderance of cases $(84.17 \%)$ was found which resembled studies by M. Uddin et al (2008) with $88 \%$ male preponderance and Kashyap et al (2005) with $78.4 \%{ }^{(6,7)}$

In our study the commonest clinical presentation was haematemesis and malaena $(50 \%)$ followed by malaena $(31.67 \%)$ and haematemesis alone $(18.33 \%)$. Other studies also showed haematemesis \& malaena as the most common clinical presentation in UGIB. Kashyap et al (2005) reported $56.8 \%$ and M.Uddin et al showed $42 \%$ cases with both haematemesis and malaena ${ }^{(6,7)}$

The commonest associated co-morbidity in UGIB was chronic liver disease $(24.17 \%)$ followed by hypertension $8.33 \%$, diabetes mellitus $3.33 \%$ COPD $(2.50 \%)$ and chronic kidney disease $(1.67 \%)$.

On upper GI endoscopy, peptic ulcer was found to be the most common cause of UGIB (54.16\%). Most studies in different parts of the world show similar findings .Paik et al (2007) in Korea reposted $50.9 \%$ Kashyap et al (2005) showed $61 \%$ and Van Leer dam ME (2008) in Netherland reported 50\% $(7,8,9)$. In this study among peptic ulcer disease duodenal ulcer was $33.33 \%$ and gastric ulcer was
$20.83 \%$. Similar findings was reported by M Uddin et al (2008) duoderal ulcer $34 \%$ and C. Sugawa et al (1990) gastric ulcer 19\%. ${ }^{(6,10)}$

Gastro esophageal varices was the second most common cause of UGIB in the present study $(24.16 \%)$ and all patients had a history of alcohol intake of varying duration. Similar findings were reported by A. Timraz et al (2011) 23\% and Paik et al (2007) $28.3 \%$. $^{(5,8)}$

Gastroduodenal erosion was found in $14.17 \%$ of patients in this study. In other studies Longstreth (1995) reported $14.3 \%$ and Faiza A Qari Showed $12 \%$ cases with gastroduoderal erosions. ${ }^{(11,12)}$

No source of bleeding could be identified in $2.50 \%$ cases in the present study, whereas Lorenlaine mentioned that in $8-14 \%$ cases source of UGIB could not be identified. ${ }^{(2)}$ Here, the result of rapid ureas test for helicobaetor pylori infection was found positive in $56.92 \%$ of peptic ulcer disease. $\mathrm{H}$. pylori was found in $60.50 \%$ of deodenal ulcer $48.00 \%$ of gastric ulcers and only $17.67 \%$ of cases with erosive mucosal disease.

Van Leerdam ME (2005) reported H.pylori infection in $50 \%$ of patients with peptic ulcer disease $^{(6)}$ John Del valle (2008) in a compilation of data from three meta analysis reported the incidence of H.pylori infection in gastric ulcer as 30 to $70 \%$ and duodenal ulcer as $50-70 \%$.

The commonest associated risk factor was alcohol $(35.82 \%)$ and steroids $(3.25 \%)$ in patients with peptic ulcer disease and erosive gastroduodenal disease. Alcohol take was found to be different in studies of different geographical areas ranging from 10\% (A. Timraz, 2011) ${ }^{(5)}$ to $70 \%$ (Fiore et al, 2000). (12) It depends on many factors like geographic distribution, religion, custom etc. Alcohol intake was found to be high probably because of taking traditional homemade alcohol and its association with local customs.

\section{CONCLUSION}

Observations made in the study reveal that peptic ulcer disease is the most common cause of UGIB in this part of the country. Helicobacter pylori was associated with more than half of the cases of peptic 
ulcer disease. Hence all patients with peptic ulcer disease should be tested for H.Pylori infection and eradication treatment given. Alcohol was found to be the commonest avoidable associated risk factor. Hence patient education in this aspect may prove to be fruitful in bringing down the number of cases of UGIB.

\section{BIBLIOGRAPHY}

1. Kankaria AG, Fleischer DE. The critical care management of non-variceal upper gastro-intestinal bleeding. Critical Care Clinics 1995; 347-68.

2. Loren Laine: Helicobacter pylori and Complicated Ulcer Disease. The American Journal of Medicine, July 1996.

3. John Del Valle: Peptic Ulcer Disease and related diseases, Harrisons principles of internal Medicine, $17^{\text {th }}, \mathrm{Ed}$

4. S.Mustafa, N.Ajayi and A.Sheru (2009) : Aetiology of Upper gastrointestinal bleeding in North-Eastern Nigeria: A Retrospective Endoscopic study. The Internet journal of Third World Medicines 2009, Vol-8.

5. A.Timraj et al (2011): Acute Upper Gastrointestinal Bleeding in Morocco : What have changed? ISRN Gastroenterology, Volume 2011, Article ID457946

6. M Uddin et al (2008): Etiology of Upper Gastrointestinal Haemorrhage in a teaching hospital. TAJ 2008; 21(1): 53-57.

7. Kashyap et al: A clinical profile of acute upper gastrointestinal bleeding at moderate altitude : JIACM 2005; 6(3) :224-8.

8. Paik et al : Clinical characteristics of acute upper gastrointestinal bleeding in a tertiary carereferral center. Korean Journal of Gastro-enterology. 2007 Jul;50(1): 26-35.

9. Van Leerdam ME. Epidemiology of acute gastrointestinal bleeding. Best Pract res Gastroenterol, 2008; 22(2): 209-24.

10. C.Sugawa et al (1990). Upper GI bleeding in an urban hospital. Etiology, recurrence and prognosis. Ann Surg. 1990 October 212(4): 521-527.
11. Longstrength GF. Epidemiology of hospitallizetion for acute upper gastrointestinal haemorrhage- A population based study. Ann J of Gastroenterology.1995 Feb; 90(2) 206-10.

12. Faiza A Qari: Major causes of upper gastrointestinal bleeding at Abdul Aziz University, Jeddah, Kuwait Medical Journal 2001,33(2): 127-130.

13. F.Di Fiore, S.Lecleire, V. Merle et al, "Changes in characteristics and outcome of acute upper gastrointestinal haemorrhage : A comparision of epidemiology and practisee between 1996 and 2000 in a multicentric French study." European Journal of Gastroenterology and Hepatology, vol 17, no.6 pg 641-647,2005. 